ORIGINAL ARTICLE

\title{
Attitudes and Beliefs of Pig Farmers and Wild Boar Hunters Towards Reporting of African Swine Fever in Bulgaria, Germany and the Western Part of the Russian Federation
}

\author{
T. Vergne ${ }^{1}$, C. Guinat ${ }^{1,2}$, P. Petkova ${ }^{3}$, A. Gogin ${ }^{4}$, D. Kolbasov ${ }^{4}$, S. Blome ${ }^{5}$, S. Molia ${ }^{6}$, J. Pinto Ferreira ${ }^{7}$, \\ B. Wieland ${ }^{1}$, H. Nathues ${ }^{1,8}$ and D. U. Pfeiffer ${ }^{1}$ \\ 1 Veterinary Epidemiology, Economics and Public Health Group, Royal Veterinary College, London, UK \\ 2 Pirbright Institute, Pirbright, UK \\ 3 Bulgarian Food Safety Agency, Sofia, Bulgaria \\ 4 State Research Institution National Research Institute for Veterinary Virology and Microbiology of Russia, Pokrov, the Russian Federation \\ 5 Friedrich-Loeffler-Institut, Greifswald - Insel Riems, Germany \\ ${ }^{6}$ Centre de Coopération Internationale en Recherche Agronomique pour le Développement, Montpellier, France \\ 7 SAFOSO Inc., Bern, Switzerland \\ ${ }^{8}$ Clinic for Swine, Vetsuisse Faculty, University of Berne, Berne, Switzerland
}

\section{Keywords:}

African swine fever; reporting; behaviour; surveillance; farmers; hunters

\section{Correspondence:}

T. Vergne. Veterinary Epidemiology, Economics and Public Health Group, Royal Veterinary College, Hawkshead Lane, Hatfield AL97TA, London, UK. Tel.: +44 17076670 39; Fax: +44 17076665 74;

E-mail: tvergne@rvc.ac.uk

Received for publication January 29, 2014

doi:10.1111/tbed.12254

\section{Summary}

This study investigated the attitudes and beliefs of pig farmers and hunters in Germany, Bulgaria and the western part of the Russian Federation towards reporting suspected cases of African swine fever (ASF). Data were collected using a web-based questionnaire survey targeting pig farmers and hunters in these three study areas. Separate multivariable logistic regression models identified key variables associated with each of the three binary outcome variables whether or not farmers would immediately report suspected cases of ASF, whether or not hunters would submit samples from hunted wild boar for diagnostic testing and whether or not hunters would report wild boar carcasses. The results showed that farmers who would not immediately report suspected cases of ASF are more likely to believe that their reputation in the local community would be adversely affected if they were to report it, that they can control the outbreak themselves without the involvement of veterinary services and that laboratory confirmation would take too long. The modelling also indicated that hunters who did not usually submit samples of their harvested wild boar for ASF diagnosis, and hunters who did not report wild boar carcasses are more likely to justify their behaviour through a lack of awareness of the possibility of reporting. These findings emphasize the need to develop more effective communication strategies targeted at pig farmers and hunters about the disease, its epidemiology, consequences and control methods, to increase the likelihood of early reporting, especially in the Russian Federation where the virus circulates.

\section{Introduction}

African swine fever (ASF) is a haemorrhagic disease in domestic pigs, with a mortality rate that can reach $100 \%$ in its hyperacute form and for which there is currently no vaccine available (Sánchez-Vizcaíno et al., 2012). Originating from Africa, it has expanded its geographical distribution into the Caucasus and Eastern Europe since 2007, where it is presently considered to be endemic (Gogin et al., 2012). The recent detection of the ASF virus in wild boar found dead within the European Union (Lithuania and Poland), and the possibility of disease spread through wildlife (De la Torre et al., 2015), trade of pigs and pig products (Mur et al., 2012a; Costard et al., 2013), movement of people, 
vehicles and food waste (Mur et al., 2012b) have raised concerns about the economic consequences of a potential ASF introduction into the EU pig production sector (FAO, 2013). To implement effective control measures against ASF, there is an urgent need for more reliable surveillance systems, especially for their passive surveillance component which is a key aspect for early detection (Hadorn et al., 2008). Although quantitative evaluation of surveillance effectiveness is necessary to appropriately interpret surveillance outputs, identifying gaps in passive surveillance by investigating pig farmers' and hunters' willingness to report suspected cases of ASF is of major importance.

Behaviours of field actors towards reporting animal diseases have already been investigated in different settings and for different diseases, and a variety of factors were shown to be associated with willingness to report disease outbreaks. For example, Elbers et al. (2010) showed that the lack of knowledge and uncertainty about the clinical signs, the lack of trust in veterinary authorities or the feeling of shame of having the disease on the farm could influence the probability of reporting clinical suspicions of avian influenza in the Netherlands. In Bolivia, Limon et al. (2014) identified the lack of institutional credibility and differences in priorities between livestock keepers and official veterinary services as the main barriers for reporting of livestock diseases.

The aim of this study was to describe the attitudes and beliefs of hunters and pig farmers in Bulgaria, Germany and the western part of the Russian Federation, towards reporting suspicions of ASF, and to identify factors influencing this behaviour, based on a web-based questionnaire survey. The results of this study will help to design adapted communication strategies for improving the effectiveness of passive surveillance.

\section{Materials and Methods}

\section{Study area}

The questionnaire survey was conducted in Bulgaria, Germany and the western part of the Russian Federation. Each of the three study areas represents a different disease situation: ASF is circulating in the western part of the Russian Federation (FAO, 2013), Bulgaria is free of ASF but at high risk of introduction through boat movements in the Black sea (Mur et al., 2012b) and Germany is also free but has been suggested to have the highest probability of importing infected live pigs from other European Union (EU) member states during the high risk period if the virus was introduced into the Schengen area (Nigsch et al., 2013).

With almost 30 million pigs (15.2\% of the total pig population of the EU), Germany had the largest pig population in the EU in 2012 (source: FAOSTAT). Germany also has the highest imports of live pigs and pig products in the EU
(Nigsch et al., 2013). The pig population in Bulgaria represents only $0.005 \%$ of the EU's total (Eurostat, 2013). In 2012, 17.3 million pigs were present in the Russian Federation (source: FAOSTAT), of which around $85.4 \%$ were located in the Western part of the country (FAO, 2013). Since the introduction of ASF in 2007, free ranging pig production has been prohibited in the Russian Federation although it is believed to be still practiced (Gogin et al., 2012).

Wild boar (Sus scrofa) are common across Europe with much higher densities in Western than in Eastern Europe and the Russian Federation (FAO, 2013). Across all three study areas, wild boar populations are increasing, as a result of changes in hunting practices, climate change and widespread availability of agricultural crops as food supply (Gortazar et al., 2000; Acevedo et al., 2006). In some regions of the Russian Federation, wild boar are hunted intensively in an attempt to decrease population density (EFSA, 2006). Such control measures are controversial as they are believed to lead to increased dispersal movements of wild boar which may eventually result in further spread of ASF (EFSA, 2014). Descriptive data on the number of hunters in the three study areas are limited.

In the three study areas, passive surveillance of ASF and other notifiable swine diseases (classical swine fever, etc.) relies on reporting of suspected cases by farmers and hunters. By law, farmers and hunters are required to immediately report to the local veterinary authorities the presence of domestic pigs with suspicious clinical signs or lesions or the finding of wild boar carcasses. Any suspect cases are then further investigated by sending samples to a diagnostic laboratory. In some parts of the Russian Federation, hunters receive financial incentives for hunting wild boar.

\section{Questionnaire survey}

Two anonymous web-based questionnaires were designed to address the following questions: (i) which factors are associated with pig farmers' intention to report suspected cases of ASF, (ii) which factors are associated with hunters' decision to submit samples from harvested wild boar for diagnostic testing, and (iii) which factors are associated with hunters' decision to report wild boar carcasses.

\section{Development of the questionnaire}

Separate questionnaires were developed for collecting data from pig farmers and hunters. The questionnaire investigated the six different drivers of behaviour specified in the theory of planned behaviour (Ajzen, 1985): beliefs in the effectiveness of the behaviour, beliefs in the consequences of the behaviour, social pressure, motivation to comply with social norms, beliefs in being able to achieve 
the behaviour and factors inhibiting ability to achieve behaviour. Both questionnaires were developed in English, tested by two hunters and two pig husbandry experts known by the authors to check for potential problems with interpretation of questions, and subsequently translated into the three relevant languages by two natives from each of the three study areas. The final web-based versions were developed and made available online using the SurveyMonkey ${ }^{\circledR}$ software (available at: www.surveymonkey.com). For both questionnaires, the introduction section contained the informed consent information and explained the purpose of the questionnaire survey. It was also specified explicitly that the responses would be treated anonymously. All questions were closed or semiclosed, and the questionnaires were estimated to take less than $15 \mathrm{~min}$ to complete. To assess attitudes and beliefs, participants were asked to answer several questions using a Likert scale with five categories (for example 'very often', 'often', 'sometimes', 'rarely', 'never' or 'I strongly agree', 'I agree', 'I disagree', 'I strongly disagree', 'I have no opinion').

The questionnaire for pig farmers was structured into four sections comprising 36 items in total. The first section collected data on the farm background (including farm age, herd size, production type, etc.). For this section, appropriate response options were defined based on the opinion of co-authors with knowledge about pig farming systems (Germany: HN; Bulgaria: PP; Russian Federation: AG, DK). The second section established farmers' perception of ASF. The third section investigated motivations for reporting suspected cases, and the fourth section investigated reasons for not reporting.

The questionnaire for hunters was structured into three sections comprising 46 items in total. The first section collected data on hunter background (including frequency of hunting, species hunted, perceived role in wildlife surveillance, etc.). For this section, appropriate response options were defined based on the opinion of co-authors with knowledge about hunting practices (Germany: SB; Bulgaria: PP; Russian Federation: AG, DK). The second section investigated behaviours towards diagnostic testing of harvested wild boar (in general, not specifically for ASF), and the third section investigated behaviours towards reporting any wild boar carcasses found.

For investigating motivations for reporting (or not reporting), respondents were asked about their agreement with specified reasons for reporting (or not reporting) suspected ASF cases. For example, farmers were asked to express their level of agreement (I strongly agree, I agree, I disagree, I strongly disagree or I have no opinion) with the following statement: 'A reason for you not to report a suspicion of ASF may be that you believe you can handle the outbreak by yourself.

\section{Data collection}

The survey was administered to a convenience sample of pig farmers and hunters. In early 2013, the electronic links to the questionnaires were distributed in each of the selected study areas to (i) pig farmers' associations, (ii) selected large pig veterinary practices and (iii) hunters' associations, with the request to forward them to their members or clients. Before distributing the questionnaire, information seminars were held in Germany at meetings of the pig farmers' associations to describe the purpose of the study. Responses to the questionnaires were gathered from the three countries over a period of 8 weeks.

\section{Statistical analyses}

\section{Modelling the attitude}

For the data on pig farmers, the outcome of interest was the answer to the following question: 'If you were to have a suspicion of ASF in your farm (e.g. observation of unusually high mortality over a short period of time) what would be your most likely reaction?' Possible responses were grouped to produce a binary outcome such that one of the two outcome categories represented the following answers: 'I would wait a few days to see what happens before thinking about reporting' or 'I would try to control the disease by myself or 'I would try to sell my pigs as soon as possible'. The other outcome category was the answer: 'I report it immediately'.

For the data on hunters, the binary outcomes of interest were answers to the two following questions: (i) 'How do you process harvested wild boar?' (one of the two outcome categories represented the answer: 'I process it myself without testing it for any disease'; the other represented the following three response options: 'I process it myself and take biological samples to a veterinarian' or 'I take the carcass to a veterinarian for meat inspection' or 'I take it to a slaughter house for processing') and (ii) 'If you ever found a wild boar carcass, what did you do with it?' (one of the two outcome categories represented the response options: 'I left it where I found it without doing anything' or 'I buried it'; the other represented the response options: 'I reported it to a veterinarian or a game keeper' or 'I took either the whole wild boar carcass or a biological sample to a veterinarian').

For each of the three analyses, observations with missing values in the associated outcome variable were excluded from the modelling process. As part of the model development, univariable associations between each outcome and risk factor variable were investigated using chi-squared tests (or Fisher's exact tests if at least one expected count was less than 5). Risk factor variables with a $P$-value below 0.2 were selected to be included in multivariable logistic regressions. Pairwise collinearity was tested between all selected risk factor variables by 
computing Cohen's kappa coefficient (Cohen, 1960), and pair-wise collinearity was considered significant if the absolute value of the coefficient exceeded 0.7. For the multivariable regressions, stepwise backward elimination was performed based on the Akaike Information Criterion (AIC). When the difference in AIC was less than 2, the most parsimonious model was selected (Burnham and Anderson, 1998). All analyses were performed using the R software (R-Development-Core-Team, 2008).

\section{General considerations}

Because the number of respondents was low for some study areas, responses were analysed together, including study area as a covariate. If the study area was significant as a main effect, interactions between the study area and other risk factor variables included in the model were tested. Given the large number of potential risk factor variables, we simplified some answers for the analysis: for example, respondents answering 'I strongly agree' or 'I agree' were combined into the category 'I agree' and those responding 'I disagree' or 'I strongly disagree' into the category 'I disagree'. Some respondents only completed small part of the questionnaire. Since it was assumed that their responses would be unreliable, only the subset of respondents that completed at least $50 \%$ of the questions was included. To be able to run a complete case analysis, the missing values were represented as a new risk factor category called 'unknown opinion'.

\section{Results}

Number of respondents

A total of 316 farmers and 568 hunters responded to the respective questionnaires. After excluding the individuals who responded to less than $50 \%$ of the questions, there remained 22 pig farmers from Germany ( $92 \%$ of the initial respondents), 171 from Bulgaria (75\%) and 50 from the western part of the Russian Federation (78\%) and 158 hunters from Germany (79\%), 188 from Bulgaria (61\%) and 20 from the western part of the Russian Federation $(34 \%)$.

\section{Farmers}

If they had a suspicion of ASF, $87 \%(211 / 243)$ of the responding farmers would report it immediately (the same day) while $13 \%$ (32/243) would wait for a few days to see what happens before thinking about reporting, would try to control the disease without the assistance of veterinary services, or would try to sell their pigs as soon as possible. These figures were similar between countries since the proportions of responding farmers who would report immediately were $88 \%(150 / 171)$ in Bulgaria, $91 \%(20 / 22)$ in Germany and $82 \%(41 / 50)$ in the western part of the Russian Federation.

Descriptive statistics for respondents who answered more than $50 \%$ of the questions are provided in Table 1. The majority of respondents were involved in commercial pig production (61\%), especially in Germany where all respondents belonged to this category. In addition, most German respondents had more than 11 sows in their pig herd, and have been keeping pigs for more than 10 years, while these variables were more evenly distributed in the western part of the Russian Federation and in Bulgaria. In the western part of the Russian Federation, $42 \%$ of the respondent farmers declared receiving a high or very high amount of information on ASF from veterinarians, the government, pig industry organisations or the press. This percentage decreases to $31 \%$ and $9 \%$ for the Bulgarian and the German respondents, respectively. For each country, veterinarians appeared to be the most important source of information compared with the professional press, the government and the swine industry. The 14 variables that were significant at $P<0.2$ in the univariable analysis are presented in Table 2. No pairwise collinearity was detected between these variables.

Table 1. Typology of the farmers who answered at least $50 \%$ of the questions stratified by country

\begin{tabular}{|c|c|c|c|c|c|c|c|c|}
\hline & \multicolumn{2}{|l|}{ Bulgaria } & \multicolumn{2}{|l|}{ Germany } & \multicolumn{2}{|c|}{ The Russian Federation } & \multicolumn{2}{|l|}{ Total } \\
\hline & Number & $\begin{array}{l}\% \text { of Bulgarian } \\
\text { respondents }\end{array}$ & Number & $\begin{array}{l}\% \text { of German } \\
\text { respondents }\end{array}$ & Number & $\begin{array}{l}\% \text { of Russian } \\
\text { respondents }\end{array}$ & Number & $\begin{array}{l}\% \text { of } \\
\text { respondents }\end{array}$ \\
\hline $\begin{array}{l}\text { Farmers with professional/ } \\
\text { commercial production }^{a}\end{array}$ & 91 & 55 & 22 & 100 & 31 & 62 & 145 & 61 \\
\hline $\begin{array}{l}\text { Farmers who have been } \\
\text { keeping pigs for } \\
\text { more than } 10 \text { years }\end{array}$ & 79 & 48 & 20 & 91 & 20 & 40 & 119 & 50 \\
\hline $\begin{array}{l}\text { Farmers who have more than } \\
11 \text { sows in their farms }\end{array}$ & 60 & 37 & 14 & 70 & 28 & 57 & 102 & 44 \\
\hline
\end{tabular}

${ }^{\mathrm{a}}$ Farmers were considered to have a professional/commercial production if they sold pigs to a middleman or directly to a slaughterhouse. 
Table 2. Variables statistically significantly associated with farmers' intention to immediately report a suspected case of African swine fever in univariable analysis (at $P$-value $<0.2$ using chi-squared tests)

\begin{tabular}{|c|c|c|c|c|}
\hline \multirow[b]{2}{*}{ Explanatory variable } & \multirow[b]{2}{*}{ Response alternatives } & \multicolumn{2}{|c|}{ Response variable } & \multirow[b]{2}{*}{$P$-value } \\
\hline & & $1^{a}$ & $0^{a}$ & \\
\hline \multirow{2}{*}{$\begin{array}{l}\text { Farmer's perceived importance } \\
\text { of his/her role in pig disease surveillance }\end{array}$} & High & 175 & 22 & \multirow[t]{2}{*}{0.131} \\
\hline & Low & 36 & 10 & \\
\hline \multirow{2}{*}{$\begin{array}{l}\text { Expected delay for a veterinarian to come } \\
\text { and investigate the suspicion }\end{array}$} & Less than a day & 189 & 23 & \multirow[t]{2}{*}{0.012} \\
\hline & More than a day & 22 & 9 & \\
\hline \multirow[t]{2}{*}{ Expected delay for a laboratory result } & Less than a week & 142 & 12 & \multirow[t]{2}{*}{0.002} \\
\hline & More than a week & 69 & 20 & \\
\hline \multirow{4}{*}{$\begin{array}{l}\text { Expected change of the reputation } \\
\text { in case of reporting a suspicion }\end{array}$} & Improved & 51 & 2 & \multirow[t]{4}{*}{0.019} \\
\hline & Damaged & 25 & 9 & \\
\hline & Unchanged & 83 & 11 & \\
\hline & No opinion & 52 & 10 & \\
\hline \multicolumn{5}{|l|}{$\begin{array}{l}\text { Level of agreement with the belief } \\
\text { that a reason for them not } \\
\text { to report a suspicion is because (of)... }\end{array}$} \\
\hline \multirow{3}{*}{$\begin{array}{l}\text { Fear that all the pigs in the } \\
\text { farm will be culled }\end{array}$} & Agree & 94 & 22 & \multirow[t]{3}{*}{$0.039 *$} \\
\hline & Disagree & 94 & 8 & \\
\hline & No or unknown opinion & 23 & 2 & \\
\hline \multirow[t]{3}{*}{ Fearing it is not African swine fever } & Agree & 61 & 16 & \multirow[t]{3}{*}{0.056} \\
\hline & Disagree & 99 & 10 & \\
\hline & No or unknown opinion & 51 & 6 & \\
\hline \multirow{3}{*}{$\begin{array}{l}\text { It is more terrible to report a suspected } \\
\text { case that proves to be a false } \\
\text { alarm than to miss a case }\end{array}$} & Agree & 47 & 14 & \multirow[t]{3}{*}{$0.044^{*}$} \\
\hline & Disagree & 136 & 15 & \\
\hline & No or unknown opinion & 28 & 3 & \\
\hline \multirow[t]{3}{*}{ Fearing that there will be too much fuss } & Agree & 61 & 17 & \multirow[t]{3}{*}{$0.034^{*}$} \\
\hline & Disagree & 122 & 13 & \\
\hline & No or unknown opinion & 28 & 2 & \\
\hline \multirow[t]{3}{*}{ Lack of knowledge on how or who to report } & Agree & 13 & 5 & \multirow[t]{3}{*}{$0.117^{*}$} \\
\hline & Disagree & 171 & 25 & \\
\hline & No or unknown opinion & 27 & 2 & \\
\hline \multirow[t]{3}{*}{ Being able to handle the outbreak by themselves } & Agree & 8 & 5 & \multirow[t]{3}{*}{$0.021 *$} \\
\hline & Disagree & 173 & 25 & \\
\hline & No or unknown opinion & 30 & 2 & \\
\hline Fearing of going out of the business & Agree & 65 & 19 & $0.005^{*}$ \\
\hline & Disagree & 123 & 10 & \\
\hline & No or unknown opinion & 23 & 3 & \\
\hline Fearing of penalties from the government & Agree & 44 & 15 & $0.007^{*}$ \\
\hline & Disagree & 139 & 13 & \\
\hline & No or unknown opinion & 28 & 4 & \\
\hline Mistrust in government officials & Agree & 26 & 10 & $0.029 *$ \\
\hline & Disagree & 155 & 18 & \\
\hline & No or unknown opinion & 30 & 4 & \\
\hline Not wanting to be part of a reporting procedure & Agree & 19 & 7 & $0.120 *$ \\
\hline & Disagree & 161 & 21 & \\
\hline & No or unknown opinion & 31 & 4 & \\
\hline
\end{tabular}

a1: would report the suspicion immediately; 0: would wait for a few days to see what happens before thinking about reporting or would try to control themselves the disease in the farm or would try to sell the pigs as soon as possible.

*A Fisher's exact test was used instead of the chi-squared test because at least one of the expected numbers was less than 5.

The results of the multivariable analyses are shown in Table 3. The final logistic model included three variables. Farmers who would immediately report a suspected outbreak are statistically significantly more likely to expect to receive a result from the diagnostic laboratory within a week $(\mathrm{OR}=4.55 ; 95 \%$ confidence interval $=[2.00 ; 10.92])$. Additionally, an expected impact on their reputation in their local community was also associated with the willingness to report: farmers who would not report immediately are much more likely to believe that their reputation would 
Table 3. Variables included in the final multivariable logistic regression with farmers' intention to immediately report a suspected case of African swine fever as outcome variable

\begin{tabular}{|c|c|c|c|c|}
\hline Explanatory variable & Categories & Number of respondents & OR & $95 \% \mathrm{Cl}$ \\
\hline \multirow[t]{2}{*}{ Expected delay for a laboratory result } & More than a week & 89 & Ref & Ref \\
\hline & Less than a week & 154 & 4.55 & $2.00-10.92$ \\
\hline \multirow{4}{*}{$\begin{array}{l}\text { Expected change of the reputation } \\
\text { in case of reporting a suspicion }\end{array}$} & Reputation improved & 53 & Ref & Ref \\
\hline & Reputation damaged & 34 & 0.09 & $0.01-0.39$ \\
\hline & Reputation unchanged & 94 & 0.24 & $0.04-1.01$ \\
\hline & Unknown opinion & 62 & 0.12 & $0.02-0.54$ \\
\hline \multirow{3}{*}{$\begin{array}{l}\text { Level of agreement with the } \\
\text { belief that a reason for them not to } \\
\text { report a suspicion is because of being } \\
\text { able to handle the outbreak by themselves }\end{array}$} & Disagree & 209 & Ref & Ref \\
\hline & Agree & 13 & 0.16 & $0.04-0.62$ \\
\hline & No or unknown opinion & 21 & 2.39 & $0.61-16.00$ \\
\hline
\end{tabular}

be adversely affected if they were to report a suspicion $(\mathrm{OR}=1 / 0.09=11.1 \quad[2.6 ; 100])$. Finally, farmers who would immediately report a suspicion are statistically significantly more likely to disagree with the statement 'a reason for you not to report a suspicion is because you believe you can handle the outbreak by yourself than respondents who would not report immediately. In other words, respondents who would not report immediately are more likely to justify their attitude by the belief they can control the outbreak themselves $(\mathrm{OR}=1 / 0.16=6.25[1.61 ; 25])$. The study area was not associated to the outcome variable.

\section{Hunters}

In the three study areas, a large majority of respondents spent more than 10 days per year hunting (96\% of German hunters, $72 \%$ in Bulgaria and $85 \%$ in the western part of the Russian Federation). Data on hunting experience showed that $57 \%$ of investigated German hunters had been hunting for more than 20 years whereas this proportion was lower at $36 \%$ and $17 \%$ for the western part of the Russian Federation and Bulgaria, respectively. Wild boar was the game most often hunted for $85 \%$ of German respondents, and $91 \%$ of Bulgarian respondents. In the western part of the Russian Federation, this number decreased to $36 \%$, with wild birds being the most common game for $57 \%$ of Russian respondents.

\section{Testing harvested wild boar}

Overall, 52\% (189/366) of responding hunters indicated that they usually subject harvested wild boar to diagnostic testing, either by taking biological samples or the carcass to a veterinarian or by taking it to the slaughter house for processing. With $62 \%$ (117/188), this proportion was higher for Bulgarian compared with German (42\%; 67/158) and Russian hunters $(25 \%$; $5 / 20)$. Variables that were significant at $P<0.2$ in the univariable analysis are presented in Table 4. No pairwise collinearity was detected between these variables.
The final logistic model included three variables (Table 5). In Bulgaria, hunters were statistically significantly more likely to have their harvested wild boar tested than in the western part of the Russian Federation $(\mathrm{OR}=1 / 0.23=4.35 \quad[1.59 ; 14.29])$ and Germany $(\mathrm{OR}=1 / 0.41=2.44[1.56 ; 3.85])$. In addition, for hunters who do not usually submit samples from harvested wild boar for diagnostic testing, presence of lesions on the carcass was more often mentioned as a reason for testing compared with those who generally submit samples for diagnostic testing, but the associated odds-ratio was not statistically significantly different from zero $(\mathrm{OR}=2.38[0.74 ; 9.09])$. Finally, hunters who do not usually submit samples were most likely (although the difference was not statistically significant neither) to believe that a lack of awareness of the possibility to test hunted wild boar was a reason for not reporting it $(\mathrm{OR}=1 / 0.57=1.75 \quad[0.87 ; 3.57]) . \quad$ No interaction between the study area and the other significant variables could be detected within our dataset.

\section{Reporting of wild boar carcasses}

The number of responses included in this model corresponded to $41 \%(149 / 366)$ of all responses from hunters, because inclusion was conditional on having already found a wild boar carcass. Overall, 83\% (123/149) of the hunters who had ever found a wild boar carcass declared having reported its presence to either a veterinarian or game keeper. This figure is similar between Bulgaria (87\%; 92/106), Germany $(71 \% ; 23 / 34)$ and the western part of the Russian Federation $(78 \% ; 7 / 9)$. Variables that were statistically significant at $P<0.2$ in the univariable analysis are presented in Table 6. Collinearity was detected between the levels of agreement with the belief that a reason for not reporting a wild boar carcass is lack of awareness of the possibility to report it and with the belief that a reason for not reporting a wild boar carcass is lack of knowledge about how to report it $(\kappa=0.71)$. We decided to only include the former variable in the multivariable analysis. 
Table 4. Variables statistically significantly associated with hunters' behaviour towards having harvested wild boar subjected to diagnostic testing in univariable analysis (at $P$-value $<0.2$ using chi-squared tests)

\begin{tabular}{|c|c|c|c|c|}
\hline \multirow[b]{2}{*}{ Explanatory variable } & \multirow[b]{2}{*}{ Response alternatives } & \multicolumn{2}{|c|}{ Response variable } & \multirow[b]{2}{*}{$P$-value } \\
\hline & & $1^{\mathrm{a}}$ & $0^{\mathrm{a}}$ & \\
\hline \multirow[t]{3}{*}{ Country } & Bulgaria & 117 & 71 & \multirow[t]{3}{*}{$<0.001$} \\
\hline & Germany & 67 & 91 & \\
\hline & The Russian Federation & 5 & 15 & \\
\hline \multirow[t]{3}{*}{ Hunting experience } & Less than 10 years & 60 & 55 & \multirow[t]{3}{*}{0.012} \\
\hline & Between 11 and 20 years & 71 & 49 & \\
\hline & More than 20 years & 58 & 73 & \\
\hline \multirow[t]{2}{*}{ Level of awareness regarding African swine fever } & High & 73 & 40 & \multirow[t]{2}{*}{0.001} \\
\hline & Low & 116 & 137 & \\
\hline \multicolumn{5}{|c|}{ Level of agreement with the belief that a reason for them to report for testing a hunted wild boar is. . } \\
\hline \multirow[t]{3}{*}{ Because it shows suspicious lesions of a disease } & Agree & 175 & 150 & \multirow[t]{3}{*}{0.001} \\
\hline & Disagree & 9 & 5 & \\
\hline & No or unknown opinion & 5 & 22 & \\
\hline \multirow{3}{*}{$\begin{array}{l}\text { To ensure the food is safe to consume whatever } \\
\text { the presence of suspicious lesions }\end{array}$} & Agree & 181 & 157 & \multirow[t]{3}{*}{0.022} \\
\hline & Disagree & 6 & 10 & \\
\hline & No or unknown opinion & 2 & 10 & \\
\hline \multicolumn{5}{|c|}{ Level of agreement with the belief that a reason for them not to report for testing a hunted wild boar is because (of)... } \\
\hline \multirow{3}{*}{$\begin{array}{l}\text { Lack of awareness about the possibility to } \\
\text { subject it to diagnostic testing }\end{array}$} & Agree & 20 & 23 & \multirow[t]{3}{*}{0.031} \\
\hline & Disagree & 162 & 136 & \\
\hline & No or unknown opinion & 7 & 18 & \\
\hline \multirow{3}{*}{$\begin{array}{l}\text { Lack of knowledge on how to proceed for } \\
\text { subjecting it to diagnostic testing }\end{array}$} & Agree & 20 & 25 & \multirow[t]{3}{*}{0.009} \\
\hline & Disagree & 164 & 135 & \\
\hline & No or unknown opinion & 5 & 17 & \\
\hline \multirow[t]{3}{*}{ Reporting is troublesome } & Agree & 31 & 36 & \multirow[t]{3}{*}{0.077} \\
\hline & Disagree & 147 & 121 & \\
\hline & No or unknown opinion & 11 & 20 & \\
\hline
\end{tabular}

a1: usually biological samples are brought to the veterinarian or the carcass is brought to the veterinarian for meat inspection or the carcass is brought to the slaughterhouse for processing; 0: usually the hunted wild boar is processed by the hunter without reporting it to be tested for any disease.

Table 5. Variables included in the final multivariable logistic regression with hunters' behaviour towards having harvested wild boar subjected to diagnostic testing as outcome variable

\begin{tabular}{|c|c|c|c|c|}
\hline Explanatory variable & Categories & $\begin{array}{l}\text { Number of } \\
\text { respondents }\end{array}$ & OR & $95 \% \mathrm{Cl}$ \\
\hline \multirow[t]{3}{*}{ Country } & Bulgaria & 188 & Ref & Ref \\
\hline & Germany & 158 & 0.41 & $0.26-0.64$ \\
\hline & The Russian federation & 20 & 0.16 & $0.05-0.46$ \\
\hline \multirow{3}{*}{$\begin{array}{l}\text { Level of agreement with the belief that a reason for them to report for } \\
\text { testing a hunted wild boar is because it shows suspicious lesions of a disease }\end{array}$} & Disagree & 14 & Ref & Ref \\
\hline & Agree & 325 & 0.42 & $0.11-1.35$ \\
\hline & No or unknown opinion & 27 & 0.08 & $0.02-0.37$ \\
\hline \multirow{3}{*}{$\begin{array}{l}\text { Level of agreement with the belief that a reason for them } \\
\text { not to report for testing a hunted wild boar is because of lack } \\
\text { of awareness about the possibility to subject it to diagnostic testing }\end{array}$} & Disagree & 298 & Ref & Ref \\
\hline & Agree & 43 & 0.57 & $0.28-1.15$ \\
\hline & No or unknown opinion & 25 & 0.42 & $0.15-1.08$ \\
\hline
\end{tabular}

The results of the multivariable analysis are shown in Table 7. The final logistic model included two variables. First, hunters were significantly less likely to report the presence of a wild boar carcass in Germany than in Bulgaria $(\mathrm{OR}=0.31[0.12-0.86])$. Second, hunters who did not report the presence of a wild boar carcass were significantly more likely to believe that a lack of awareness of the possibility to report a carcass was a reason for them not to report it, compared with those who reported it $(\mathrm{OR}=1 / 0.24=4.17 \quad[1.43$; 12.5]). No interaction between these two variables was detected. 
Table 6. Variables statistically significantly associated with hunters' behaviour towards reporting wild boar carcasses in univariable analysis (at $P$-value $<0.2$ using chi-squared tests)

\begin{tabular}{|c|c|c|c|c|}
\hline \multirow[b]{2}{*}{ Explanatory variable } & \multirow[b]{2}{*}{ Response alternatives } & \multicolumn{2}{|c|}{ Response variable } & \multirow[b]{2}{*}{$P$-value } \\
\hline & & $1^{\mathrm{a}}$ & $0^{\mathrm{a}}$ & \\
\hline \multirow[t]{3}{*}{ Country } & Bulgaria & 92 & 14 & \multirow[t]{3}{*}{$0.072^{*}$} \\
\hline & Germany & 24 & 10 & \\
\hline & The Russian Federation & 7 & 2 & \\
\hline \multirow[t]{2}{*}{ Level of awareness regarding African swine fever } & High & 49 & 5 & \multirow[t]{2}{*}{0.078} \\
\hline & Low & 74 & 21 & \\
\hline \multicolumn{5}{|c|}{ Level of agreement with the belief that a reason for them not to report a wild boar carcass is because (of)... } \\
\hline \multirow[t]{3}{*}{ Lack of awareness about the possibility to report it } & Agree & 16 & 8 & \multirow[t]{3}{*}{$0.010^{*}$} \\
\hline & Disagree & 100 & 14 & \\
\hline & No or unknown opinion & 7 & 4 & \\
\hline \multirow[t]{3}{*}{ Lack of knowledge about how to report it } & Agree & 18 & 11 & \multirow[t]{3}{*}{$0.010 *$} \\
\hline & Disagree & 98 & 14 & \\
\hline & No or unknown opinion & 7 & 1 & \\
\hline \multirow[t]{3}{*}{ Reporting is troublesome } & Agree & 20 & 10 & \multirow[t]{3}{*}{$0.017^{*}$} \\
\hline & Disagree & 94 & 13 & \\
\hline & No or unknown opinion & 9 & 3 & \\
\hline
\end{tabular}

${ }^{a}$ 1: when a dead wild boar was found, a biological sample was brought to the vet, or the presence of a dead wild boar was reported to the game keeper or to the vet; 0 : when a dead wild boar was found, the carcass was left where found without doing anything.

*A Fisher's exact test was used instead of the chi-squared test because at least one of the expected numbers was less than 5.

Table 7. Variables included in the final multivariable logistic regression with hunters' behaviour towards reporting wild boar carcasses as outcome variable

\begin{tabular}{|c|c|c|c|c|}
\hline Explanatory variable & Categories & Number of respondents & OR & $95 \% \mathrm{Cl}$ \\
\hline \multirow[t]{3}{*}{ Country } & Bulgaria & 106 & Ref & Ref \\
\hline & Germany & 34 & 0.31 & $0.12-0.86$ \\
\hline & The Russian federation & 9 & 0.59 & $0.11-4.59$ \\
\hline \multirow{3}{*}{$\begin{array}{l}\text { Level of agreement with the belief that a reason for them } \\
\text { no to report a wild boar found dead is because of lack } \\
\text { of awareness about the possibility to report it }\end{array}$} & Disagree & 114 & Ref & Ref \\
\hline & Agree & 24 & 0.24 & $0.08-0.70$ \\
\hline & No or unknown opinion & 11 & 0.06 & $0.01-1.13$ \\
\hline
\end{tabular}

\section{Discussion}

The objective of this study was to investigate the factors associated with the attitude of farmers and hunters towards reporting suspected ASF cases in different parts of central and Eastern Europe. It is important to be aware that the study design, data collection method and sampling approach result in several limitations for this dataset which will be discussed in more detail below. The results of the analyses therefore need to be interpreted very cautiously. The models developed in this study do not explicitly identify causal relationships between the different variables and the outcome of interest; they only show statistical associations between beliefs and behaviours. We still believe that given the lack of information about the reporting behaviours and associated drivers the findings presented here provide a basis for informing the design of more effective communication strategies aimed at increasing the likelihood of reporting.

\section{Farmers}

Three significant factors were shown to be associated with farmers' willingness to immediately report suspected cases of ASF (Table 3). One of these factors is that they expect the diagnostic laboratory to provide a diagnostic test result within 7 days. This concern could potentially be addressed by appropriately resourcing diagnostic laboratories and veterinary services and to communicate these efforts back to farmers. Similar to the situation reported for avian influenza in the Netherlands (Elbers et al., 2010), farmers who indicated that they would not immediately report a suspicion of ASF are more likely to be concerned about the adverse effect that reporting suspect ASF cases might have on their reputation within their local community. Moreover, farmers who would not report immediately are more likely to answer that being able to control an outbreak themselves is a reason for not reporting a suspicion. These results highlight the need to mitigate the potential for 
adverse social consequences of reporting a suspected case, and to improve farmers' knowledge about the economic consequences of the disease. Increasing communication efforts targeted at farmers seems particularly relevant, since a large proportion of farmers $(58 \%, 69 \%$ and $91 \%$ in the RF, Bulgaria and Germany, respectively) considered they receive medium, low or very low amounts of information regarding ASF.

The variable 'study area' was not statistically significantly associated with willingness to report suspicions. This result needs to be interpreted considering that farmers in Germany and Bulgaria may have heard about ASF through the farming press or government awareness campaigns, but because the virus is not present in these countries they are unlikely to perceive the infection as an immediate threat. In contrast, ASF virus is known to circulate in the western part of the Russian Federation, so Russian farmers should be more familiar with the disease and its impact and were therefore expected to be more inclined to report suspicions. Reasons for absence of a study area effect might be 2 -fold. First, it can be that in the case of the western part of the Russian Federation, farmers simply lack incentives to report or that communication strategies are poorly effective so that their reporting rate is similar to reporting rates in countries free of ASF. Second, this absence of a study area effect may be linked to study design issues such as insufficient statistical power or sampling bias as discussed below.

Because it is very unlikely that responding farmers have experienced an ASF outbreak in their farm, the model outcome variable represented their intention (i.e. their expected behaviour if they had a suspicion of ASF) rather than their real behaviour. Given that the intention is only a predictor of the actual behaviour that would occur in the future, the two may be different as highlighted by many behavioural studies (Sheeran, 2002). As an example, Gallois et al. (1992) showed that $57 \%$ of their study participants failed to act according to their intention of using condoms, while $10 \%$ of their participants ended up using condoms although they claimed they would not. In our context, we believe that the social norms and the legislation regarding disease notification have a strong influence on farmers' intentions to report a suspicion. Therefore, it is likely that farmers who responded they would not report immediately will act accordingly, while an unknown proportion of farmers who pretended they would report immediately will eventually wait a few days before considering to report or will try to sell their pigs as soon as possible. As a consequence, we believe that the true proportion of farmers who will eventually report a suspicion is smaller than the proportion of farmers who said this was their intention ( $87 \%$ of respondents). Assuming that these discrepant respondents are most likely to provide answers for the investigated risk variables similar to those who did express their intention to not report immediately, this bias is likely to have decreased the power of our analysis.

\section{Hunters}

Hunters from the western part of the RF were less likely to subject harvested wild boar to diagnostic testing than those from Bulgaria and Germany (Table 5). Moreover, the likelihood of reporting wild boar carcasses was also lower in the western part of the RF than in Bulgaria (although the difference was not statistically significant). Knowing that ASF is present in wild boar in most of the western regions of the RF, this finding strongly stresses the need for the RF to improve the awareness of Russian hunters with respect to infectious disease in wildlife and their willingness to contribute to surveillance programmes.

In addition, hunters indicating that they do not report the presence of wild boar carcasses frequently attributed this behaviour to being unaware of the possibility to report. Because the quick progression of the disease in infected wild boar leads to death in a few days (Blome et al., 2012), the detection of the disease through active surveillance of wild boar is very unlikely (FAO, 2013); the likelihood of identifying the virus is probably higher in carcasses than in hunted wild boar. Therefore, although about $80 \%$ of hunters indicated they report carcasses, it would seem worthwhile to enhance this surveillance component by improving communication strategies targeted at hunters for maximizing their likelihood to report wild boar carcasses. Efforts should be made to make reporting as easy as possible, or to incentivise hunters to report by setting up a reward or compensation scheme, and to ensure rapid availability of laboratory results.

\section{Limitations of the current study}

Despite of sending reminders to the target groups of potential study participants, response rates were low for some subgroups such as German farmers (24 farmers completed the questionnaire at least partially) or Russian hunters (59). In addition, $31 \%$ of farmers' and hunters' responses were excluded from the analyses because they answered less than $50 \%$ of the questions. Most of these excluded respondents stopped answering the questionnaire after completing the background section, indicating that they lost interest. Using face-to-face questionnaires or phone questionnaires would probably have resulted in a higher response rate, more complete responses and in a better representativeness of the sample. But it would have required more effort to standardize the interview process ensuring consistency between 
the three different languages, as well as additional resource for data entry. Furthermore, performing interviews even for the current sample of 316 hunters and 568 farmers would have had significant cost implications. Finally, with online questionnaire surveys, anonymity is more obvious to the respondents, making them more likely to provide truthful answers.

An important issue is the representativeness of the study population with respect to the target population, which were all pig farmers and hunters in the three study areas. The source population differed from the target population in that it only comprised of pig farmers and hunters who used the internet. This means that the source population might have been biased towards the subpopulation of pig farmers and hunters with better education, higher incomes and therefore potentially higher awareness of disease surveillance. This bias may have been even stronger in Bulgaria and the Russian Federation where the heterogeneity among farmers and hunters is likely to be larger than in Germany. This selection bias may explain the high proportion of pig farmers who responded they would immediately report the presence of suspected cases ( $86 \%$ of responding pig farmers). As a consequence, a generalization of the results to the whole population of pig farmers and hunters in the selected countries should not be attempted.

Due to the large number of investigated explanatory variables, many covariate combinations were associated with very low numbers of respondents. In fact, in the final model for farmers, $31 \%(15 / 48)$ and $25 \%$ (12/48) of the cells involved zero and only one observation, respectively. This resulted in a low statistical power, which may explain the absence of statistically significant interactions between the variable 'study area' and the different risk factor variables. The differences in the epidemiological, social and economic contexts of the three study areas make it unlikely that the risk factor effects do not vary between them. Another objective of the study was to determine if there were subgroups amongst farmers and hunters who were less likely to report a suspected ASF case, test harvested wild boar or report wild boar carcasses. However the study did not identify particular subgroups that could be targeted in information campaigns to increase the likelihood of reporting in a cost-benefit manner.

This study provides insights on the attitudes and beliefs of pig farmers and hunters in relation to reporting of suspected cases of ASF. The results raise significant concerns with respect to their contribution to passive surveillance of ASF, which may be a consequence of lack of awareness. Considering the major economic and animal welfare significance of ASF, further sociological studies involving indepth interviews of field actors should be conducted to improve our understanding of the drivers of human behaviour in relation to ASF reporting.

\section{Acknowledgements}

We thank Milen Georgiev and Svetlana Buzdugan for their support with the translation of questionnaires. We also thank Dr Pablo Alarcon for the useful discussions about the principles of decision-making processes. We are also very grateful to William Gilbert for improving the readability of this paper. Finally, we would like to thank two anonymous reviewers who provided comments that improved significantly the manuscript. This work has been carried out as part of the European Union funded project ASFORCE (KBBE.2012.1.3-02).

\section{References}

Acevedo, P., M. A. Escudero, R. Munoz, and C. Gortazar, 2006: Factors affecting wild boar abundance across an environmental gradient in Spain. Acta Theriol. 51, 327-336.

Ajzen, I., 1985: From intentions to actions: A theory of planned behavior. In: Kuhl, J. and J. Beckmann (eds), Action-Control: From Cognition to Behavior, pp. 11-39. Springer, Heidelberg.

Blome, S., C. Gabriel, K. Dietze, A. Breithaupt, and M. Beer, 2012: High virulence of African swine fever virus caucasus isolate in European wild boars of all ages. Emerg. Infect. Dis. 18, 708.

Burnham, K., and D. Anderson, 1998: Model Selection and Inference: A Practical Information-Theoretic Approach. Springer, New York.

Cohen, J., 1960: A coefficient of agreement for nominal scales. Educ. Psychol. Measur. 20, 37-46.

Costard, S., B. A. Jones, B. Martínez-López, L. Mur, A. de la Torre, M. Martínez, F. Sánchez-Vizcaíno, J. M. Sánchez-Vizcaíno, D. U. Pfeiffer, and B. Wieland, 2013: Introduction of African swine fever into the European Union through illegal importation of pork and pork products. PLoS ONE 8, e61104.

De la Torre, A., J. Bosch, I. Iglesias, M. J. Muñoz, L. Mur, B. Martínez-López, M. Martínez, and J. M. Sánchez-Vizcaíno, 2015: Assessing the Risk of African Swine Fever Introduction into the European Union by Wild Boar. Transbound. Emerg. Dis. 62, 272-279.

EFSA, 2006: The Community Summary Report on trends and sources of Zoonoses, Zoonotic Agents, Antimicrobial Resistance and Food-borne outbreaks in the EU in 2005. EFSA J., http://www.efsa.europa.eu/en/efsajournal/doc/94r.pdf (accessed May 28, 2014).

EFSA, 2014: Evaluation of possible mitigation measures to prevent introduction and spread of African swine fever virus through wild boar. EFSA J. 12, 3616-3638.

Elbers, A. R., M. J. Gorgievski-Duijvesteijn, K. Zarafshani, and G. Koch, 2010: To report or not to report: a psychosocial investigation aimed at improving early detection of avian influenza outbreaks. Rev. Sci. Tech. 29, 435-449.

Eurostat, 2013: Agriculture, forestry and fishery statistics. Available online at: http://epp.eurostat.ec.europa.eu/cache/ 
ITY_OFFPUB/KS-FK-13-001/EN/KS-FK-13-001-EN.PDF (accessed February 3, 2014).

FAO, 2013: African Swine Fever in the Russian Federation: Risk factors for Europe and beyond. Empress Watch, 28.

Gallois, C., Y. Kashina, D. Terry, M. McCamish, P. Timmins, and A. Chauvin, 1992: Safe and unsafe sexual intentions and behavior: the effects of norms and attitudes. J. Appl. Soc. Psychol. 22, 1521-1545.

Gogin, A., V. Gerasimov, A. Malogolovkin, and D. Kolbasov, 2012: African swine fever in the North Caucasus region and the Russian Federation in years 2007-2012. Virus Res. 173, 198-203.

Gortazar, C., J. Herrero, R. Villafuerte, and J. Marco, 2000: Historical examination of the status of large mammals in Aragon, Spain. Mammalia 64, 411-422.

Hadorn, D. C., S. S. Haracic, and K. D. Stärk, 2008: Comparative assessment of passive surveillance in disease-free and endemic situation: example of Brucella melitensis surveillance in Switzerland and in Bosnia and Herzegovina. BMC Vet. Res. 4, 52.

Limon, G., E. G. Lewis, Y. Chang, H. Ruiz, M. A. Balanza, and J. Guitian, 2014: Using mixed methods to investigate factors influencing reporting of livestock diseases: a case study among smallholders in Bolivia. Prev. Vet. Med. 113, 185-196.
Mur, L., B. Martínez-López, M. Martínez-Avilés, S. Costard, B. Wieland, D. U. Pfeiffer, and J. M. Sánchez-Vizcaíno, 2012a: Quantitative risk assessment for the introduction of African swine fever virus into the European Union by legal import of live pigs. Transbound. Emerg. Dis. 59, 134-144.

Mur, L., B. Martínez-López, and J. M. Sánchez-Vizcaíno, 2012b: Risk of African swine fever introduction into the European Union through transport-associated routes: returning trucks and waste from international ships and planes. BMC Vet. Res. 8, 149.

Nigsch, A., S. Costard, B. A. Jones, D. U. Pfeiffer, and B. Wieland, 2013: Stochastic spatio-temporal modelling of African swine fever spread in the European Union during the high risk period. Prev. Vet. Med. 108, 262-275.

R-Development-Core-Team, 2008: R: A Language and Environment for Statistical Computing. R Foundation for Statistical Computing, Vienna, Austria, ISBN 3-900051-07-0, http:// www.r-project.org (accessed April 5, 2013).

Sánchez-Vizcaíno, J. M., L. Mur, and B. Martínez-López, 2012: African swine fever: an epidemiological update. Transbound. Emerg. Dis. 59, 27-35.

Sheeran, P., 2002: Intention-behavior relations: a conceptual and epirical review. European Rev. Soc. Psych. 12, 1-36. 